\title{
The effect of a family psychoeducational program on relatives of patients suffering from schizophrenia
}

SATOKO SOTA, MA, ${ }^{1}$ SHINJ I SHIMODERA, MD, PhD, ${ }^{1}$ MASARU KII, MD, ${ }^{2}$

KAYOKO OKAMURA, MD, ${ }^{2}$ KOICHIROU SUTO, MD, PhD, ${ }^{2}$ MITURU SUWAKI, MD, ${ }^{3}$

HIRO KAZU FUJ ITA, MD, PhD, ${ }^{4}$ RYOSUKE FUJ ITO, MD, ${ }^{1}$ SHIMPEI INO UE, MD, PhD, 5

${ }^{1}$ Department of Neuropsychiatry, Kochi Medical School, 2TOSA Hospital, ${ }^{3}$ GEIYO Hospital, ${ }^{4}$ Kochi Health Sciences Center, 5 Kochi University

\begin{abstract}
Aims: Family psychoeducational programs have been shown to be effective in terms of knowledge acquirement and relapse prevention; however, few studies have looked at whether one mode of educational method is more effective than a nother. The a im of this study was to compare several modes of educational approaches and to elucidate which mode of education is more effective than others. Methods: 110 rela tives of 95 patients with sc hizophrenia received three types of family psychoeducational programs between J a nuary 1995 and September 2003: a small group with two sessions (P1), a large group with nine sessions (P2), and a large group with five sessions (P3). In addition to the demographic data, we measured acquired knowledge using the modified
\end{abstract}


Knowledge A bout Schizophrenia Interview, family expressed emotion (EE), and relapse episodes. Results: Overall there were significant increases in many KASI subcategory scores after the three programs, in mothers in particular. The change in KASI scores showed the low EE group as able to be highly educated and the relatives of non-relapsers being more effectively educated. As for the mode of the family psychoeducational program, the P1 and P2 groups surpassed the P3 in terms of knowledge acquired. Conclusions: O ur findings suggest that the effects of family psychoeducation may depend not on the number of members or sessions but on the time spent on the program per member.

Key words: expressed emotion, family psychoeducational program, knowledge, relapse, sc hizophrenia 


\section{Introduction}

The psycho-educational approach specifically targeting the relatives of sc hizo phrenia patients originates from a family expressed emotion (EE) study in the $1970 s^{1}$. With the EE study dividing families into two groups; fa milies with high EE and those with low EE, it was found that discharged patients returning to a high EE family had a 3 to 4 times higher risk of relapse than patients who retumed to a low EE family ${ }^{1}$. Based on this family diagnosis, psychoeducation for family members began in the 1980s, and its effectiveness in terms of relapse prevention has been widely confirmed. ${ }^{2-4}$ Consequently, some EE studies were performed in Japan, and the relation of EE to schizophrenia relapse ${ }^{-6}$, social function 7 , and symptoms of depression ${ }^{8}$ became apparent. In addition, interventions through family psychoeducation were performed, and its effectiveness in preventing relapse was verified ${ }^{9}$.

With respect to the mode of intervention for families, there are common basic components of psychoeducation: education about the illness and its course, training in coping and problem-solving skills, improved communication, and stress reduction ${ }^{10}$. Specifically, psychoeduc ation plays a n important role, providing fa mily members with psychologic al and social support by offering information on the causes and symptoms as well as methods to deal with the patient in a way that is ea sily und erstood, while taking into account the mental sta te of the family11. 
Many studies assessing the effectiveness of fa mily intervention a re a vailable; for example, fa mily work conducted by Leff et al. was successful in curtailing the rate of schizophrenia relapse. The fa mily work here consisted of psychiatric staff making home visits to families living with a patient ${ }^{12}$. Another example of family intervention is behavio ral family therapy including communic ation skills and problem-solving techniques using role playing ${ }^{13}$. It was not only helpful in decreasing the relapse rate, but also contributed to reduce the maintenance drug use. The psychoeducation program, which consisted of lectures a ttended by $20-40$ a dult fa mily members of sc hizophrenia patients in the community, also showed positive results such as a reduced relapse rate and hospitalization period, improved psychiatric symptoms, and the recovery of certain social functions ${ }^{14}$.

We have tried three pattems of family psychoeducational programs and have reported on small part of the find ing $\mathrm{s}^{15}$. This paper comprehensively presents the findings based on data collected through our family psychoeducational programs. The purpose of this study was to elucidate which mode of education was more effective than others and to investigate the influence of other variables such as cha racteristic s of fa milies, EE, and relapse on the acquirement of knowledge. 


\section{Methods}

\section{Subjects}

The subjects were i)the relatives of persons with sc hizophrenia; who were admitted to Tosa hospital, an affiliated hospital of Kochi Medic al School and ii) the relatives of patients treated in other hospitals, between J a nuary 1995 and September 2003. The diagnostic criteria of schizophrenia met the DSM-IV (Americ an Psychiatric Association, 1994) and/or ICD-10 (World Health Organization, 1992) criteria. Of 324 relatives who attended the program, data were available from 110: 61 mothers (55\%), 27 fathers (25\%), seven siblings (6\%), six husbands (5\%), five wives (5\%), one grandmother, one a unt, one common-law wife and one sister-in-law. The average age of relatives was 55.5 and the average years of education were 11.4. We obtained consent to participate in the study from the relatives. The remaining 214 relatives did not partic ipate because of refusal of consent, extreme old age, and so on.

The number of patients was 84 in Tosa Hospital and 11 in other hospitals. The characteristic s of the patients were obtained only from those treated in Tosa Hospital: 50 men (53\%), an average age of 32.5 years, a verage years of education at 11.2 years, an average age at onset of 24.9 years, a verage duration of illness of 7.7 years, and an average number of previous ho sp ita liza tions of 3.9. 


\section{Programs of family psyc hoeducation}

A. Small group with two sessions (P1)

Initially, we formed a small group of two to three families attending two sessions from J a nuary 1995 to March 1998. The number of partic ipants differed each time with mostly three to four persons. The staff consisted of two psychiatrists, one psychiatric social worker, and one clerk. The teaching materials were two videos produced by Zenkaren (National Alliance of Fa milies with Menta lly III) and our own pamphlet. On the first day we gave information on the causes, symptoms and course of the illness, and on the second day, details of the recovery process and relapse followed by questions and answers. Each session la sted about two hours ${ }^{15}$.

B. Large group with nine sessions (P2)

The second type of family psychoeducational program was a large group attending nine sessions from April 1998 to December 2000 (P2). The number of participants largely varied from ten to twenty. The staff consisted of three psychiatrists, three psychiatric social workers and three clerks. Using our own textbook, we gave much more information than in P1 with a question-andanswer session of about one hour. The topics of the nine sessions were epidemiology, general ideas about the disease, etiology, symptomatology, 
course, drug treatment, psychosocial treatment, long-term outcome, and community resources. After each lecture, we held group therapy for about one hour that aimed at problem solving. Ea ch session lasted a round two hours.

C. Large group with five sessions (P3)

The third type was a large group attending five sessions from J a nuary 2001 to September 2003. Aga in, the number of participants la rgely va ried from ten to twenty. The staff consisted of two psychiatrists, two social workers, and two clerks. Using our own video and text, ("Understanding sc hizo phrenia", available at Tosa Hospital), we gave more information than in $\mathrm{P} 1$, but less than in P2 with a question-and-answer time of about one hour. The to pics of the five sessions were symptomatology, etiology, drug treatment, psychosocial treatment, long-term outcome, and community resources. After each lecture, we held supportive group therapy for about one hour. Each session lasted about two hours.

Some participants attended more than two programs. As the effect of the program was primarily judged by the change in the score, we included all the participants in the above programs in the analysis.

\section{Measures}


a. Change of knowledge

In order to probe the extent of the subjects' knowledge about schizophrenia, we administered the modified Knowledge A bout Schizophrenia Interview (KASI) ${ }^{16}$ before the first session and after the last session. KASI is a n open-ended questionnaire consisting of 21 questions and covering the diagnosis, symptomatology, etiology, course of the condition and prognosis, medic ation, and wish of relatives for more information. Omitting questions unrelated to the a im of this study, we selected eleven questions such as "Has a nyone told you the name of the condition?", or "What is the cause of the condition?" The extent of knowledge of each category was scored with our own scale (Table 1). The inter-rater reliability of the score, ANOVA ICC, was excellent: 0.97 . The scoring was not always performed blindly to the program types.

b. Family expressed emotion

As we have long conducted studies on family expressed emotion and schizophrenia, we included some relatives who had been interviewed using the Camberwell Family Interview (CFI). Each relative was classified as high EE or low EE according to the conventional criteria 2 .

c. Relapse 
Relapse can be defined in many ways. We simply adopted the definition as readmission to a psychiatric hospital within one year after the end of the sessions. We used a non-parametric test to compare the scores of KASI using SPSS 12.0J for Windows.

\section{Results}

\section{Effects of educational programs on family members}

There were significant increases of the scores in the KASI diagnosis, etiology, course/outc ome and trea tment for all participants, as shown in Table 2; however, there was no difference in the area of symptomatology. With parents and mothers, significant score increase was found in the same categories as those found in all relatives, while with fathers, this favorable difference was found in three categories, with spouses in one category, and with children in none.

\section{EE and the effects of educ ational programs (Table 3)}

Thirty-two relatives were interviewed using CFI and the number of relatives classified into high EE and low EE was equal, with sixteen in each group. Of the sixteen relatives classified into high $\mathrm{EE}$, seven were critic al/hostile, ten were emotionally overinvolved, and one had both characteristics. There were no differences in KASI score at the baseline between high and low EE relatives. 
In the low EE group, however, there were significant score increases in the KASI etiology, course/outc ome, and treatment score. In the high EE group, these favorable changes were found only in KASI treatment. These results indic a te that low EE relatives were more effectively educ ated in our programs.

\section{Relapse and effects of educational programs (Table 4)}

Of the eighty-four patients who could be followed up, twenty-five suffered a relapse, with a relapse rate of $29.8 \%$. There were no differences in patient/relative characteristic s and in the KASI sc ore at the ba seline between relapsers and non-relapsers. As for the individual KASI sc ore comparison between baseline and after sessions, non-relapsers showed a significant increase of the score in the diagnosis, etiology, course/outc ome and treatment while relapsers showed an increase only in the etiology and trea tment. These results indic a te that rela tives of non-relapsers were more effectively educated in our sessions. Further, the relapse rate of high and low EE was $38 \%$ and $31 \%$, respectively, showing no relationship between EE status and relapse.

\section{Programs and their effects (Table 5)}

There were no differences of family members, EE status and relapse rate between three groups. At the baseline, the KASI diagnosis score was lower in 
the P1 group than in the other two groups, and the KASI cause score was higher in the P2 group than in the other two groups. As for the individual KASI score comparison between the baseline and after sessions, 1) the P1 group showed significant increase of the score in the diagnosis, etiology, course/outcome and treatment, and 2) the P2 group showed signific ant increase of the score in the diagnosis and course/outcome, and the trend of increase in treatment, while 3) the P3 group showed no change in all KASI categories. As was described in the Methods, some participants attended more than two programs. The results were not altered after removing the duplic ation of repeated partic ipation families.

\section{Disc ussion}

Our results showed that family psychoeduc a tiona I programs had substantial effects on relatives. Firstly, relatives were able to acquire knowledge related to schizophrenia, particularly conceming the diagnosis, etiology, course/prognosis, and trea tment. Our results were consistent with previous reports. Using the same tool, Barrowclough et al..17, demonstrated acquired knowledge in the areas of diagnosis, etiology, symptomatology, course/prognosis and management. Nisio ${ }^{18}$ also reported a n education effect in the areas of symptomatology and prognosis. It could be said that psychoeducation is useful for rela tives to understand the illness as a whole. 
The relationship between education and the EE that low EE relatives acquired more knowledge than those with high EE seems to be inconsistent with the findings by Berkowitz et al. ${ }^{19}$ Contrary to the U.K., the relatives in Japan may receive little reporting from professionals and the level of knowledge at baseline was almost the same between high and low EE relatives. In addition to this, emotional reactions during the program may interfere with knowledge ac quirement in high EE relatives. Care for relatives, partic ularly those showing emotional reactions may be necessary during the sessions.

The extent of acquired knowledge of relatives of non-relapsers was superior to that of relatives of relapsers. These findings agree with the previous reports such as Berkowitz et al.16*19 that family psychoeducation increased knowledge and brought about changes in family attitudes leading to a decrease in the relapse rate. Ishibashi20 showed the similar results using the same instrument as ours. As were shown in the results, there were no differences of relapse rate between the three programs, while significant differences of the extent of acquired knowledge were found between P1 and P2/P3. Although we can not rule out the possibility of confounding factors such as usage of antipsychotic drugs, it is suggested that education has power of relapse prevention in non-relapsers independent of style of programs. 
Our findings seem to be unique in that they were consecutively obtained at the same institution. We assumed that with our own video/text and after several trials, the most recent P3 program was most effective; however, the results were against expectations; the P3 program was least effective. It may be that the program effects depend on hypothetical time allotted to each participant in each session. This is calculated by 1 ) dividing the number of session hours by partic ipating members and 2) multiplying it by the number of sessions. It is roughly 60-80 minutes in P1, 54-108 minutes in P2, and 30-60 minutes in P3. In family educational programs, the partic ipants' time involved in the program may impact the consequences, offering suggestions for developing teaching styles of family education ${ }^{21}$.

There a re some limitations of our study. First, the sample may not represent the relatives because we could not collect questionna ires from all the partic ipants; second, the small number of relatives weakened the statistic al power; third, relapse was not defined as worsening of symptoms or functions; fourth, a more powerful research design such as randomized controlled trial will be needed to answer our questions. In addressing these limitations, we will be able to point the way towards a more precise type of family psychoeducational program.

In conclusion, the effects of family psychoeducation in terms of acquirement of knowledge depend on the time spent on the program per 
member, which suggest the way toward a more precise type of family psychoeducational program.

\section{Ac knowledgments}

The authors express their thanks to Ms Hiroko Itoh, Manager of the Community Lia ison Room of the hospital for a llowing access to patients in her care. 


\section{REFERENCES}

1. Brown GW, Birley J LT, Wing JK. Influence of fa mily life on the course of schizo phrenic disorders: A replication. Br. J. Psychiatry 1972; 121:241-258.

2. Leff J, Vaughn C. Expressed Emotion in Families. Guilford Press, New York, NY, 1985. (J apanese translation by Mino Y, Ushijima S. Kongo-shuppan, Tokyo, 1991.)

3. Bebbington $P$, Kuipers $L$. The predic tive utility of expressed emotion in schizo phrenia: an aggregate analysis. Psychol. Med. 1994; 24:707-718.

4. Butzlaff RL, Hooley J M. Expressed emotion and psychiatric relapse, a meta-a nalysis. Arch. Gen. Psychiatry 1998; 55:547-552.

5. Tanaka S, Mino Y, Inoue S. Expressed Emotion and schizophrenic course in Japan. Br. J. Psychiatry 1995; 167:794-798.

6. Mino $\mathrm{Y}$, Inoue $\mathrm{S}$, Tanaka $\mathrm{S}$, Tsuda $\mathrm{T}$. Expressed emotion a mong fa milies and course of schizophrenia in Japan : a 2-year cohort study. Schizophr. Res. 1997; 24:333-339.

7. Inoue S, Tanaka S, Shimodera S, Mino Y. Express emotion and social function. Psychiatry Res. 1997; 72:33-39.

8. Mino $Y$, Inoue S, Shimodera S, Tanaka S, Tsuda T, Yamamoto E. Expressed emotion of families and negative/depressive symptoms in schizophrenia : A cohort study in Japan. Schizophr. Res. 1998; 34:159-168.

9. Shimodera S, Mino Y, Inoue S, Tanaka S, Fujita H. Psycho-educational family intervention for schizo phrenia : Randomized control trial in J apan. Psychiatry Res. 2000; 96:141-148.

10. American Psychiatric Association: Practice guideline for the trea tment of patients with sc hizophrenia. Am. J. Psyc hia try 1997; 154(suppl):1-63. (J a panese translation by the Japanese Society of Psychiatry and Neurology. Igaku-shoin, Tokyo, 1999.)

11 . Goto M: Psycho-educational Multiple Fa mily Therapy with Fa milies of Long Term Inpatients. J a panese J oumal of Family Thera py 1991; 8(1):11-19. 
12 Leff J, Kuipers L, Berkowitz R, Eberlein-Vries R, Sturgeon D . A controlled trial of social intervention in the families of schizophrenic patients. Br. J. Psyc hiatry 1982; 141:121-134.

13 . Falloon I.R., Boyd J .L., McG ill C.W., Razani J ., Moss H.B., G ild erman A.M. Family management in the prevention of exacerbation of sc hizo phrenia : a controlled study. N. Engl. J. Med. 1982; 306:1437-1440.

14 . Mingyuan Z, Heqin Y, Cheng de $Y$, J ianlin Y, Q ingfeng Y, Peijun C, Lianfang G, J izhong Y, Guangya Q, Zhen W. et al : Effectiveness of psychoeduc ation of relatives of schizophrenic patients; a prospective cohort study in five cities of China. Int. J. Ment. Health 1993; 22:47-59.

15. Shimodera S, Motoki Y, Izumoto Y, Inoue S, Tanaka S, Segawa A, Kii M, Morisa wa N, Komatu S, Tokuhira M, Itou H, Suto K. Bunretsubyoukanja to seika tsusuru kazokuheno kyouikuto so nokyouikukouka nitsuite. (In J apa nese, Educ ation for and its effects of families living with persons with sc hizo phrenia.) Psychiat. Neurol. J ap. 1996;98(7):493.

16 . Berkowitz R, Eberlein-Freis R, Kuipers L, Leff J . Educ ating rela tives about schizo phrenia. Schizo phr Bull. 1984; 10:418-429.

17. Barrowclough C, Ta rrier N, Watts S, Vaughn C, Bamrah S, Freeman L. Assessing the functional value of relatives' knowledge about sc hizophrenia: A Preliminary Report, Br. J. Psychiatry 1987; 151:1-8.

18 . Nishio M, Horiuchi K, Ohno T, Makio K, Ohara S.

Tougoushic c houshou ka zokukyoushitsuno koukahyoukanikansurukenkyuu: KASI niyoru chishikihyouka nitsuiteno kousats (in J a panese, Research on the effect evaluation of fa mily education of schizo phrenia using KASI. Annual Report of the Research on Nervous and Mental Disorders 2002. 19. Berkowitz R, Shavit N, Leff J. Educ a ting rela tives of sc hizo phrenic patients. Soc. Psychiatry Psychiatr. Epidemiol. 1990; 25:216-220.

20 Ishibashi K, Kosonoe K, Hoshino S: Touinnniokeru ka zokukyouikupurogura mu: seishinbunretsubyou sa iha tsub oushinota meni. (in J a panese, Family education program of Takeda General Hospital 
aiming relapse prevention in schizophrenia. Takeda General Hospital J ournal 2002; 28:10-18.

2 1. Nando $M$, Kimura $M$, Yoshida $H$, Numaguchi R, Ikebuchi E. : Ka zokuguruhpu. (in Japanese, Fa mily group.) Clinic al J oumal of Psychiatric servic es. 2003;3:346-349. 
Table 1 Ratings and Anchor Points of the Modified Knowledge About Schizophrenia Interview

\section{$<$ Diagnosis $>$}

4: Knows the right disease name and recognizes the condition to be a psychiatric disorder.

3: Doesnot know the right disease name but recognizes the condition to be psychiatric disorder.

2: Admits the condition as some disorder, but does not recognize it as psychia tric.

1: $\quad$ Neverbeen told the diagnosis or can not say the disease name.

\section{< Symptoms >}

4: $\quad$ Gives a suffic iently objective expla nation for the symptoms.

3: Gives an objective expla nation for the symptoms, but it is insuffic ient.

2: Gives slightly more objective expla nation for the symptoms.

1: Gives a subjective expla nation for the symptoms or takes a critical attitude to them.

\section{$<$ Etiology $>$}

4: $\quad$ Gives an expla nation of the role of both vulnerability and stress.

3: Gives an expla nation of the role of either vulnera bility or stress.

2: $\quad$ Gives a skewed explanation such as genetic fault or wrong child rearing.

1: Gives no explanation or a totally inappropriate explanation.

\section{$<$ Course/Outc ome $>$}

4: Regards course as fluctuating, still has some hope in the

3: Regards course as fluc tuating, while outc ome as pessimistic or too optimistic.

2: Regards course as always bad, while outc ome as promising.

1: Regards course as always bad and outcome as hopeless.

\section{$<$ Treatment $>$}

4: Knows the importance of a) avoiding stressful situation, b) relatives not expressing too much womy about the patients, and c) taking medic ine regula rly, and gives a dequate assistance in terms of taking.

3: Knows the importance of a ), b) and C), while it is usua lly left to the patient to take medic ine with occa sional assistance if necessary.

2: Knows the importance of either a), b), or c), while it is usually left to the patient to take medicine.

1: Never refers to the importance of the items above and nevercomprehends the patient's taking medicine. 
Table 2 Effects of Education by Family Members

\begin{tabular}{|c|c|c|c|c|c|c|c|c|c|c|c|c|c|c|c|}
\hline & \multicolumn{3}{|c|}{ KASI diagnosis score } & \multicolumn{3}{|c|}{ KASI symptom score } & \multicolumn{3}{|c|}{ KASI etiology score } & \multicolumn{3}{|c|}{ KASI course/outcome score } & \multicolumn{3}{|c|}{ KASI treatment score } \\
\hline & Baseline & $\begin{array}{c}\text { After } \\
\text { education }\end{array}$ & $p$ value & Baseline & $\begin{array}{c}\text { After } \\
\text { education }\end{array}$ & $\mathrm{p}$ value & Baseline & $\begin{array}{c}\text { After } \\
\text { education }\end{array}$ & $p$ value & Baseline & $\begin{array}{c}\text { After } \\
\text { education }\end{array}$ & $\mathrm{p}$ value & Baseline & $\begin{array}{c}\text { After } \\
\text { education }\end{array}$ & $\mathrm{p}$ value \\
\hline \multirow{2}{*}{ All $(\mathrm{N}=110)$} & $2(1-4)$ & $2(1-4)$ & $<0.001$ & $2(1-4)$ & $2(1-4)$ & 0.660 & $3(1-4)$ & $3(1-4)$ & $<0.001$ & $3(1-4)$ & $3(1-4)$ & $<0.001$ & $2(1-4)$ & $2(1-4)$ & $<0.001$ \\
\hline & $2.2(1.0)$ & $2.6(1.0)$ & & $2.3(0.9)$ & $2.3(0.8)$ & & $2.3(0.9)$ & $2.7(0.9)$ & & $2.6(1.0)$ & $3.1(1.0)$ & & $1.8(0.8)$ & $2.3(0.8)$ & \\
\hline \multirow{2}{*}{ Parent $\quad(\mathrm{N}=88)$} & $2(1-4)$ & $2(1-4)$ & $<0.001$ & $2(1-4)$ & $2(1-4)$ & 0.73 & $3(1-4)$ & $3(1-4)$ & $<0.001$ & $3(1-4)$ & $3(1-4)$ & $<0.001$ & $2(1-4)$ & $2(1-4)$ & $<0.001$ \\
\hline & $2.3(1.0)$ & $2.7(1.0)$ & & $2.3(1.0)$ & $2.2(0.7)$ & & $2.3(1.0)$ & $2.7(0.9)$ & & $2.6(1.0)$ & $3.1(1.0)$ & & $1.8(0.8)$ & $2.4(0.8)$ & \\
\hline \multirow{2}{*}{ Mother $\quad(\mathrm{N}=61)$} & $2(1-4)$ & $2(1-4)$ & 0.003 & $2(1-4)$ & $2(1-4)$ & 0.514 & $3(1-4)$ & $3(1-4)$ & 0.003 & $3(1-4)$ & $3(1-4)$ & 0.015 & $2(1-4)$ & $2(1-4)$ & $<0.001$ \\
\hline & $2.2(0.9)$ & $2.6(1.0)$ & & $2.3(0.9)$ & $2.2(0.7)$ & & $2.3(1.0)$ & $2.7(1.0)$ & & $2.6(1.0)$ & $3.0(1.0)$ & & $1.8(0.8)$ & $2.5(0.8)$ & \\
\hline \multirow{2}{*}{ Father $\quad(N=27)$} & $2(1-4)$ & $2.5(1-4)$ & 0.144 & $2(1-4)$ & $2(1-3)$ & 0.712 & $2.5(1-4)$ & $3(1-4)$ & 0.022 & $3(1-4)$ & $3(1-4)$ & $<0.001$ & $1.5(1-4)$ & $2(1-4)$ & 0.013 \\
\hline & 2.6(1.1) & $2.9(1.0)$ & & $2.8(1.0)$ & $2.1(0.7)$ & & $2.3(1.0)$ & $2.7(0.7)$ & & $2.4(1.1)$ & $3.3(0.8)$ & & $1.7(0.8)$ & $2.2(0.8)$ & \\
\hline \multirow{2}{*}{$\begin{array}{c}\text { Spouse - overall } \\
\qquad(\mathrm{N}=11)\end{array}$} & $2(1-2)$ & $2(2-4)$ & 0.014 & $3(1-3)$ & $3(1-4)$ & 0.41 & $3(1-3)$ & $3(1-4)$ & 0.10 & $3(1-4)$ & $3(1-4)$ & 0.17 & $2(1-3)$ & $2(1-3)$ & 0.26 \\
\hline & $1.6(0.5)$ & $2.5(0.8)$ & & $2.5(0.8)$ & $2.6(0.8)$ & & $2.5(0.8)$ & $2.8(0.9)$ & & $2.5(1.2)$ & $3.3(0.9)$ & & $1.7(0.8)$ & $2.0(0.6)$ & \\
\hline \multirow{2}{*}{ Wife $\quad(N=5)$} & $2(1-2)$ & 2(2-4) & 0.102 & $3(1-3)$ & $3(2-3)$ & 0.564 & $3(1-3)$ & $3(2-4)$ & 0.317 & $3(2-4)$ & $3(1-4)$ & 0.705 & $2(1-3)$ & $2(1-3)$ & 1.000 \\
\hline & $1.8(0.4)$ & $2.6(0.9)$ & & $2.4(0.9)$ & $2.6(0.5)$ & & $2.4(0.9)$ & $2.8(0.8)$ & & $3.0(1.0)$ & $2.8(1.1)$ & & $1.8(0.8)$ & $1.8(0.9)$ & \\
\hline \multirow{2}{*}{ Husband $(\mathrm{N}=6)$} & $1.5(1-2)$ & $2(2-4)$ & 0.059 & $3(1-3)$ & $3(1-4)$ & 0.564 & $3(1-3)$ & $3(1-4)$ & 0.157 & $2(1-4)$ & $4(3-4)$ & 0.705 & $1.5(1-3)$ & $2(2-3)$ & 1.000 \\
\hline & $1.5(0.5)$ & $2.3(0.8)$ & & $2.5(0.8)$ & $2.7(1.0)$ & & $2.5(0.8)$ & $2.8(1.0)$ & & $2.2(1.3)$ & $3.7(0.5)$ & & $1.7(0.9)$ & $2.1(0.4)$ & \\
\hline \multirow{2}{*}{ Children $(\mathrm{N}=7)$} & $2(1-3)$ & $2(2-4)$ & 0.14 & $3(2-4)$ & $3(2-4)$ & 0.46 & $3(1-4)$ & $3(1-4)$ & 0.78 & $3(1-4)$ & $4(2-4)$ & 0.26 & $2(1-3)$ & $2(1-4)$ & 0.10 \\
\hline & $1.9(0.7)$ & $2.6(1.0)$ & & $2.9(0.9)$ & $3.0(0.8)$ & & $2.6(1.0)$ & $2.7(1.0)$ & & $2.7(1.1)$ & $3.1(0.9)$ & & $1.9(0.9)$ & $2.1(0.7)$ & \\
\hline
\end{tabular}

Median (Range)

\section{Average(SD)}

The mean (SD) is shown to help clarify the change between the two points.

KASI: Knowledge About Schizophrenia Interview

Wilcoxon Matched-Pairs Signed-Ranks Test was used to compare the score at baseline and after educational sessions.

Significantly different items have an educational effect. 
Table 3 Effects of Education by EE Status $(n=32)$

\begin{tabular}{|c|c|c|c|c|c|c|c|c|c|c|c|c|c|c|c|}
\hline & \multicolumn{3}{|c|}{ KASI diagnosis score } & \multicolumn{3}{|c|}{ KASI symptom score } & \multicolumn{3}{|c|}{ KASI etiology score } & \multicolumn{3}{|c|}{ KASI course/outcome score } & \multicolumn{3}{|c|}{ KASI treatment score } \\
\hline & Baseline & $\begin{array}{c}\text { After } \\
\text { education }\end{array}$ & $p$ value & Baseline & $\begin{array}{l}\text { After } \\
\text { education }\end{array}$ & $p$ value & Baseline & $\begin{array}{c}\text { After } \\
\text { education }\end{array}$ & $p$ value & Baseline & $\begin{array}{l}\text { After } \\
\text { education }\end{array}$ & $p$ value & Baseline & $\begin{array}{l}\text { After } \\
\text { education }\end{array}$ & $p$ value \\
\hline \multirow{2}{*}{$\begin{array}{l}\text { HighEE } \\
(\mathrm{N}=16)\end{array}$} & $2(1-4)$ & $2(1-4)$ & 0.059 & $2(1-3)$ & $2(1-4)$ & 0.705 & $2(1-3)$ & $3(1-4)$ & 0.160 & $3(1-4)$ & $3(1-4)$ & 0.075 & $2(1-3)$ & $2(1-4)$ & 0.034 \\
\hline & $2.2(0.9)$ & $2.5(0.9)$ & & $2.0(0.8)$ & $2.0(0.6)$ & & $2.0(0.8)$ & 2.2(0.9) & & 2.6(1.1) & $3.2(1.0)$ & & $1.5(0.7)$ & $2.1(0.7)$ & \\
\hline \multirow{2}{*}{$\begin{array}{l}\text { LowEE } \\
(\mathrm{N}=16)\end{array}$} & $2(1-4)$ & $4(2-4)$ & 0.054 & $2.5(2-4)$ & $2(1-3)$ & 0.206 & $2.5(1-3)$ & $3.5(3-4)$ & 0.018 & $3(1-4)$ & $3(2-4)$ & 0.006 & $2(1-3)$ & $3(1-4)$ & 0.005 \\
\hline & $2.3(1.1)$ & $2.6(0.9)$ & & $2.6(0.8)$ & $2.4(0.5)$ & & $2.2(0.9)$ & $3.1(0.3)$ & & $2.3(1.1)$ & $3.3(0.9)$ & & $2.0(0.6)$ & $2.5(0.5)$ & \\
\hline
\end{tabular}

Median (Range)

Average (SD)

The mean (SD) is shown to help clarify the changes between the two points.

KASI: Knowledge About Schizophrenia Interview

Wilcoxon Matched-Pairs Signed-Ranks Test was used to compare the score at baseline and after educational sessions.

Mann-Whitney $U$ test was used to compare the score at baseline between the two groups showing no significant differences in all categories.

Significantly different items have an educational effect. 
Table 4 Effects of Education on Relapsers and Non-relapsers

\begin{tabular}{|c|c|c|c|c|c|c|c|c|c|c|c|c|c|c|c|}
\hline & \multicolumn{3}{|c|}{ KASI diagnosis score } & \multicolumn{3}{|c|}{ KASI symptom score } & \multicolumn{3}{|c|}{ KASI etiology score } & \multicolumn{3}{|c|}{ KASI course/outcome score } & \multicolumn{3}{|c|}{ KASI treatment score } \\
\hline & Baseline & $\begin{array}{c}\text { After } \\
\text { education }\end{array}$ & $\mathrm{p}$ value & Baseline & $\begin{array}{c}\text { After } \\
\text { education }\end{array}$ & $p$ value & Baseline & $\begin{array}{c}\text { After } \\
\text { education }\end{array}$ & $\mathrm{p}$ value & Baseline & $\begin{array}{c}\text { After } \\
\text { education }\end{array}$ & $\mathrm{p}$ value & Baseline & $\begin{array}{c}\text { After } \\
\text { education }\end{array}$ & $\mathrm{p}$ value \\
\hline \multirow{2}{*}{$\begin{array}{l}\text { Non-relapsers } \\
(\mathrm{N}=29)\end{array}$} & $2(1-4)$ & $2(1-4)$ & $<0.001$ & $2(1-4)$ & $2(1-4)$ & 0.284 & $3(1-4)$ & $3(1-4)$ & 0.015 & $3(1-4)$ & $3(1-4)$ & 0.002 & $2(1-4)$ & $2(1-4)$ & $<0.001$ \\
\hline & $2.3(0.9)$ & $2.7(1.0)$ & & $2.2(0.9)$ & $2.2(0.9)$ & & $2.4(1.0)$ & $2.7(0.9)$ & & $2.5(1.0)$ & $2.7(0.9)$ & & $2.5(1.0$ & $3.0(1.0)$ & \\
\hline \multirow{2}{*}{$\begin{array}{l}\text { Relapsers } \\
(\mathrm{N}=59)\end{array}$} & $2(1-4)$ & $2(1-4)$ & 0.217 & $2(1-4)$ & $3(2-4)$ & 0.052 & $3(1-4)$ & $3(1-4)$ & 0.008 & $3(1-4)$ & $3(1-4)$ & 0.150 & $2(1-4)$ & $2(1-4)$ & 0.013 \\
\hline & $2.2(1.1)$ & $2.5(1.0$ & & $2.4(1.0)$ & $2.7(0.6)$ & & $2.3(0.9$ & $2.8(0.8)$ & & $2.7(1.1)$ & $3.2(1.0)$ & & $1.8(0.8)$ & $2.3(0.8)$ & \\
\hline
\end{tabular}

Median (Range)

The mean (SD) is shown to help clarify the change between the two points.

KASI: Knowledge About Schizophrenia Interview

Wilcoxon Matched-Pairs Signed-Ranks Test was used to compare the score at baseline and after educational sessions.

Mann-Whitney $U$ test was used to compare the score at baseline between the two groups showing no significant differences in all categories.

Significantly different items have an educational effect. 
Table 5 Effects of Education using Different Programs

\begin{tabular}{|c|c|c|c|c|c|c|c|c|c|c|c|c|c|c|c|}
\hline & \multicolumn{3}{|c|}{ KASI diagnosis score } & \multicolumn{3}{|c|}{ KASI symptom score } & \multicolumn{3}{|c|}{ KASI etiology score } & \multicolumn{3}{|c|}{ KASI course/outcome score } & \multicolumn{3}{|c|}{ KASI treatment score } \\
\hline & Baseline & $\begin{array}{c}\text { After } \\
\text { education }\end{array}$ & $p$ value & Baseline & $\begin{array}{c}\text { After } \\
\text { education }\end{array}$ & $p$ value & Baseline & $\begin{array}{c}\text { After } \\
\text { education }\end{array}$ & $\mathrm{p}$ value & Baseline & $\begin{array}{c}\text { After } \\
\text { education }\end{array}$ & $\mathrm{p}$ value & Baseline & $\begin{array}{c}\text { After } \\
\text { education }\end{array}$ & $\mathrm{p}$ value \\
\hline \multirow{2}{*}{$\begin{array}{l}\text { P1 Program } \\
(\mathrm{N}=72)\end{array}$} & $2(1-4)$ & $2(1-4)$ & $<0.001$ & $2(1-4)$ & $2(1-4)$ & 0.423 & $2(1-4)$ & $3(1-4)$ & $<0.001$ & $3(1-3)$ & $3(1-4)$ & $<0.001$ & $2(1-3)$ & $2(1-4)$ & $<0.001$ \\
\hline & $2.0(0.9)$ & $2.5(0.9)$ & & $2.3(0.8)$ & $2.3(0.7)$ & & $2.1(0.9)$ & $2.6(0.8)$ & & $2.6(1.1)$ & $3.1(0.9)$ & & $1.7(0.7)$ & $2.2(0.6)$ & \\
\hline \multirow{2}{*}{$\begin{array}{l}\text { P2 Program } \\
(\mathrm{N}=16)\end{array}$} & $3(2-4)$ & $4(2-4)$ & 0.013 & $2(1-4)$ & $2(1-3)$ & 0.118 & $3(3-4)$ & $3.5(3-4)$ & 0.414 & $2.5(1-4)$ & $3(2-4)$ & 0.006 & $2(1-4)$ & $3(1-4)$ & 0.053 \\
\hline & $3.1(0.8)$ & $3.6(0.7)$ & & $2.4(1.2)$ & $2.0(0.7)$ & & $3.5(0.5)$ & $3.4(0.5)$ & & $2.5(0.8)$ & $3.4(0.5)$ & & $2.4(1.4)$ & $3.4(0.7)$ & \\
\hline \multirow{2}{*}{$\begin{array}{l}\text { P3 Program } \\
(\mathrm{N}=22)\end{array}$} & $2(1-4)$ & $2(1-4)$ & 0.627 & $3(1-4)$ & $3(1-4)$ & 0.680 & $3(1-4)$ & $3(1-4)$ & 0.130 & $3(1-4)$ & $3(1-4)$ & 0.550 & $1(1-3)$ & $2(1-3)$ & 0.132 \\
\hline & $2.5(0.9)$ & $2.5(0.9)$ & & $2.3(1.1)$ & $2.2(0.9)$ & & $2.4(0.9)$ & $2.7(1.0)$ & & $2.5(1.1)$ & $2.5(1.2)$ & & $1.5(0.7)$ & $1.9(0.8)$ & \\
\hline
\end{tabular}

Median (Range)

Average (SD)

The mean (SD) is shown to help clarify the change between the two points.

KASI: Knowledge About Schizophrenia Interview

$\mathrm{P} 1$ : Small group with two sessions

P2: Large group with nine sessions

P3: Large group with five sessions

Wilcoxon Matched-Pairs Signed-Ranks Test was used to compare the score at baseline and after educational sessions.

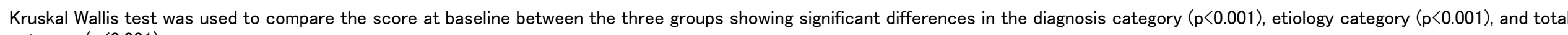
categorv $(\mathrm{p}<0.001)$.

Significantly different items have an educational effect. 